\title{
Ethnicity and Gender in Museum Representations of Human Evolution
}

\section{The Unquestioned and the Challenged in Learners' Meaning Making}

\author{
Jesús Piqueras $^{1} \mathbb{D} \cdot$ Marianne Achiam $^{2}$ (D) Susanna Edvall ${ }^{3} \cdot$ Charlotte $\mathbf{E k}^{3}$
}

Accepted: 2 December 2021 /Published online: 6 January 2022

(c) The Author(s) 2022

\begin{abstract}
Scientific representations of human evolution often embrace stereotypes of ethnicity and gender that are more aligned with socio-cultural discourses and norms than empirical facts. The present study has two connected aims: to understand how ethnicity and gender are represented in an exhibition about human evolution, and to understand how that representation influences learners' meaning making. First, we analysed an exhibition with realistic reconstructions of early hominids in a museum of natural history, to identify dualisms related to the representation of gender and ethnicity that have been recognised in research. Then, we studied the processes of meaning making in the exhibition during an out-of-school educational activity, in which groups of teenaged students explore and discuss the hominid reconstructions. Our results show that the exhibition displays human evolution in the form of a linear sequence from a primitive African prehistory to a more advanced European present. Behind this depiction of human evolution lies stereotypic notions of ethnicity and gender: notions that were incorporated into the students' meaning making during the educational activity. When students noticed aspects of ethnicity, their meaning making did not dispute the messages represented in the exhibition; these were accepted as scientific facts. Conversely, when the students noticed aspects related to gender, they often adopted a more critical stance and challenged the representations from different perspectives. We discuss the implications of our findings for exhibit design and evolution education more generally. In doing so, we offer our perspectives on the design of learning environments to salvage inherently sexist, racist, imperial science.
\end{abstract}

Jesús Piqueras

jesus.piqueras@mnd.su.se

1 Department of Mathematics and Science Education, Stockholm University, SE-106 91, Stockholm, Sweden

2 Department of Science Education, University of Copenhagen, Copenhagen, Denmark

3 Swedish Museum of Natural History, Stockholm, Sweden 


\section{Introduction}

\subsection{Evolution, Trust in Science, and Educational Challenges}

Evolution is the foundational theoretical explanation for all the life sciences, and science education has long recognised its importance (Harms \& Reiss, 2019; Smith, 2010). In fact, the importance of understanding evolution goes beyond the domain of science; among the arguments for a robust understanding of evolution are that it empowers individuals to make wise decisions about their personal lives and ultimately helps them become democratically informed citizens (Smith et al., 1995). Yet, despite its central and important role in science and science education, evolution is perhaps one of the most controversial and misunderstood scientific theories and its acceptance faces considerable challenges (Heddy \& Nadelson, 2012; Taylor \& Ferrari, 2011). From a societal perspective, public debate is often characterised by profound misconceptions of the nature of science and an acute lack of trust in science and scientists, especially with respect to biological evolution (Browning, 2015). Particularly in the educational domain, the association between trust in science and acceptance of evolution has become a concerning issue amid the growing trend of mistrust in science associated with many science developments and research (Gauchat, 2015). Thus, in a study on undergraduate students that explored the relationship between trust in science and the acceptance of evolution, Nadelson and Hardy (2015) found that lower levels of trust in science and scientists were associated with a decrease in the acceptance of evolution at three different contexts studied (macroevolution, microevolution, and human evolution). Also, from an educational perspective, learning and teaching about evolution confront important challenges. Over the years, research in science education has revealed an important number of conceptual difficulties that make it difficult for students to learn about evolution (Cummins et al., 1994; Gregory, 2009; Thagard \& Findlay, 2010). Other studies suggest that there are emotional aspects often related to different conceptions of life and beliefs that can hinder students' learning about evolution (Grimes, 2012; Seals, 2010; Thagard \& Findlay, 2010). Additionally, evolution is difficult to teach in the formal science education system (i.e. in schools) because this system tends to be based on a perception of scientific practice as the experimental testing of hypotheses (Estrup \& Achiam, 2019). Although this experimental modality is fundamental to the development of knowledge in many scientific disciplines, it is not well suited to developing the concepts of evolution. Indeed, the basic concepts of evolution are based on inductive methodologies that are not amenable to experimentation. Furthermore, the fossil and extant biological evidence that forms the basis of inductive evolution research is not readily available in the classroom (King \& Achiam, 2017). For these reasons, life science educators often turn to natural history museums (Achiam et al., 2016; Davies \& Nicholl, 2017). These institutions can be a unique complement to school-based evolution education due to their position as some of society's most trusted institutions (Britain Thinks, 2013; Museums Association, 2013), and due to the resources they have at their disposal (Diamond \& Evans, 2007; Record, 2018).

In the present study, we explore how a museum of natural history can be a resource for meaningful learning of evolution and, at the same time, provide students with opportunities to discuss scientific norms and conceptions, and recognise the power and limitations of science (Call for papers, 2021). We situate this study within a qualitative research paradigm, where we use interconnected interpretive practices to understand our subject matter (cf. Denzin \& Lincoln, 2005), namely how human evolution is represented and understood in a natural history museum. We see these representations and understandings as fundamentally 
mediated by social and historical power influences, and aim to present our findings in terms of socio-cultural criticism that can contribute constructively to redressing the injustices we find (Kincheloe \& McLaren, 2005). In this way, we engage with the overarching questions of how inherently sexist, racist, imperial science can be salvaged, and what role natural history learning environments can play in educating visitors about why and when trust in science is warranted (Call for papers, 2021).

\subsection{Learning About Human Evolution in Museums}

In general, museums offer learners experiences in a range of modalities that fit their identity-related needs in different ways (Falk \& Storksdieck, 2009). In the specific case of evolution education, natural history museums give learners the chance to see real fossils from entire evolutionary lineages, touch and handle specimens, explore vast quantities of digitised information, immerse themselves in simulations, or come face to face with realistic reproductions of extinct beings (Davies \& Nicholl, 2017; Diamond \& Scotchmoor, 2006). It is not only the museum's physical environment that provides opportunities for learning but also, from a socio-cultural perspective, the conditions for processes of meaning making that arise in the interaction with other visitors or students (Davidsson \& Jakobsson, 2012; Piqueras et al., 2008). In the particular case of teaching evolution, several studies highlight the importance of a dialogical approach that provide the students with the opportunity of thinking critically and using an 'inter-language' where colloquial expressions serve as an asset in meaning making (Olander \& Ingerman, 2011; Powers et al., 2014). Within this perspective, studies on learning about evolution in museum settings are rare but they stress the importance of activities that promote authentic inquiry, and interactions and dialogue between learners (Achiam et al., 2016; Tare et al., 2011), as well as the possibility to work with authentic questions in the process of meaning making (Anderson, 2007; Quistgaard, 2010).

Here, we focus on an inquiry-oriented teaching activity with museum exhibits, specifically realistic reconstructions of hominids in an exhibition about human evolution in a natural history museum. Recently, museum exhibits have emerged that incorporate naturalistic reconstructions of hominids as an innovative means to represent and communicate human evolution (Ceder, 2021; Smithsonian, 2020). However, as we elaborate in the following sections, the hyperrealism of these models carries with it a risk that they are perceived by non-specialists as accurate representations rather than tentative hypotheses (cf. Balter, 2009). To our knowledge, no studies have yet examined the implications of hyperrealistic hominid models for making meaning of human evolution, but a substantial body of research indicates that other representations of human evolution, in particular visual representations of early hominids, often embrace cultural stereotypes of ethnicity and gender that are more aligned with dominant notions about the lifestyle of present-day humans than empirical facts (Levin, 2010). For example, Gifford-Gonzalez (1993) found that images of female individuals in human evolution illustrations are almost always accompanied by male counterparts, although the opposite is not true. Lutz and Collins (1993) found systematic differences in the type of labour hominids were depicted doing, and the colour of their skin. Finally, in a newer study, Ash (2019) found that indigenous peoples in dioramas are often portrayed from colonialist points of view. Collectively, this research points to how, in anthropological imagery, the adult, white, male Euro-American is often linked with evolutionary progress and superiority (Ceder, 2021; Wiber, 1997). 
In the present study, we examine the implicit messages of ethnicity and gender imparted by the exhibits about human evolution in a teaching activity in the Swedish Museum of Natural History. We specifically focus on students' meaning making in the encounter with the scenes displayed in the dioramas and use our findings to discuss how the hominid reconstructions can be used to promote more equitable understandings of human evolution. Thus, our study is not about reconciling scientific conceptions of evolution with the views of museum visitors (e.g. Groß et al., 2019). Rather, it is about a more insidious phenomenon, namely the cultural stereotypes that are built into in reconstructions of our evolutionary past (Wiber, 1997), and that have important implications for the meaning making of learners who interact with those reconstructions (Scott, 2007). Therefore, the following questions have guided our study: (i) How are ethnicity and gender represented in a hominid exhibition in a natural history museum, (ii) how do these representations influence learners' meaning making about human evolution, and (iii) what are the implications for the design of learning environments that provide opportunities to discuss scientific norms and conceptions, and recognise the power and limitations of science?

\section{Method}

The present study has two connected aims: to understand how ethnicity and gender are represented in hominid exhibits, and to understand how that representation influences learners' meaning making at those exhibits. Accordingly, we carry out our data collection and analysis in two distinct steps, focusing first on the exhibits and second on learners' meaning making. In the following sections, we describe the setting of the study, the exhibition The Human Journey, and how we analysed its content. Then, we describe the educational activity that provided the data for examining learners' meaning making, and how we analysed this meaning making.

\subsection{Study Setting}

The exhibits studied here are part of the exhibition The Human Journey, located at the Swedish Museum of Natural History in Stockholm. The Swedish Museum of Natural History is Sweden's largest institution committed to the diffusion and communication of science and nature, and has about twelve permanent and four temporary exhibitions, visited by about 700000 people a year. The Human Journey opened in 2008 and features the last seven million years of human evolution, from the first bipedal hominids found in the fossil record to today. Additional evolutionary series found in the exhibition are horses and elephants.

The hominids are represented by reconstructions of the major steps in human evolution, namely Australopithecus afarensis, Homo habilis, Homo ergaster, Homo neanderthalensis, and Homo sapiens. The hominid reconstructions are placed along the central axis of the exhibition. Furthermore, there is a reconstructed Homo floresiensis set a bit apart from the central axis (Fig. 1). This study had a particular focus on three of the hominid exhibits, namely Australopithecus afarensis, Homo ergaster, and Homo neanderthalensis (Fig. 2).

The hominid reconstructions in The Human Journey are all created by paleoartist Elizabeth Daynès, who specialises in hyperrealistic models of hominids (Thompson, 2014). Hyperrealistic reconstructions such as those in The Human Journey are artistic creations, and have been discussed by paleo-anthropologists, some of whom are uncomfortable with 


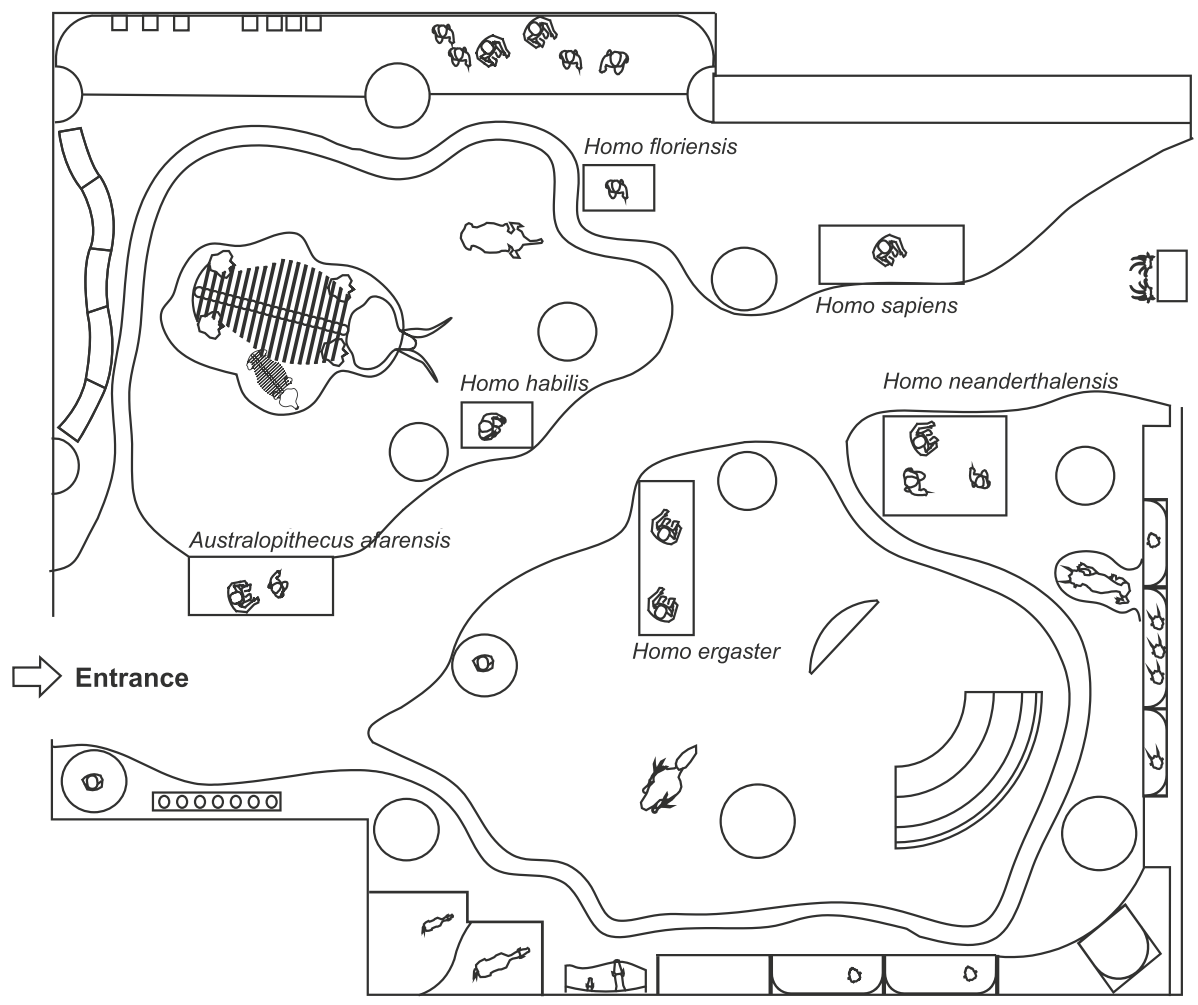

Fig. 1 Floor plan of The Human Journey, with the locations of the hominid exhibits. Image courtesy of the The Swedish Museum of Natural History, used with permission

the seemingly definitive answers the reconstructions offer to questions that remain unanswered by research (Balter, 2009). At the same time, their realism makes the reconstructions 'compellingly factual' and thus effortlessly decodable for museum visitors (GiffordGonzalez, 1993, p. 29; Levin, 2010).

The Australopithecus afarensis exhibit consists of two reconstructed individuals, one smaller female and one larger male (Fig. 2A). They are shown walking bipedally in the same direction, the smaller individual in front of the larger one. The Homo ergaster exhibit shows a young male individual (Fig. 2B), positioned in front of a reconstructed skeleton. $\mathrm{He}$ is wearing a loincloth and holding a rock in his right hand. Finally, the Homo neanderthalensis exhibit consists of three reconstructed individuals: a female, a male, and a child. All three individuals are relatively burly. The adults are walking abreast, and the child is sitting in front of them. The male has a hairy body, while the female and child have hairless bodies. The two adults are wearing loincloths. The male is carrying a dead deer on his shoulders, while the female is carrying a brace of dead birds and a rabbit over her left shoulder. 

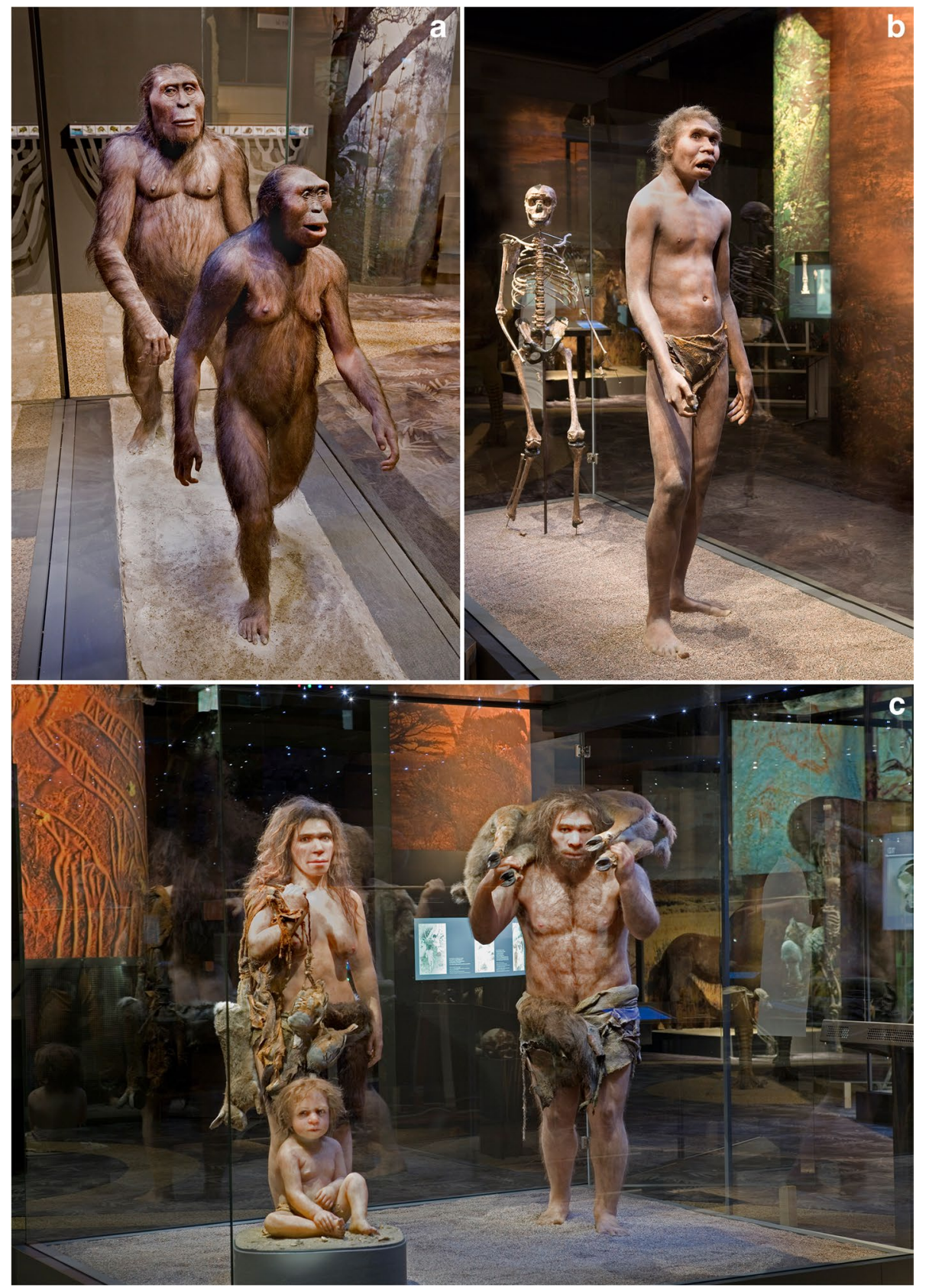

Fig. 2 Three exhibits with reconstructed hominids in the exhibition The Human Journey. A Australopithecus afarensis, female and male; B Homo ergaster, male; C Homo neanderthalensis, female, male, and infant. The exhibition includes additional reconstructions of Homo habilis, Homo floresiensis, and Homo sapiens, which are not shown here. Photos courtesy of the Swedish Museum of Natural History, used with permission 


\subsection{Analysis of the Hominid Exhibits}

We analysed the way knowledge and objects were organised in the hominid exhibits, based on the floor map of the exhibition (Fig. 1), the Museum web site, conversations with Museum professionals, field notes from our visits to the exhibition, and photos of texts and objects in the three exhibits. We analysed this multimodal data with attention to its tiers of complexity (Meng, 2004), that is its organization at the levels of museum, exhibition, and exhibit (Nicolaisen \& Achiam, 2020). Our analytical lens consists of a number of dualisms related to the representation of gender and ethnicity that have been identified in research on visual representations of early hominids and human evolution (described in the following). We present the analysis of The Human Journey in the 'Findings' section to illustrate the characteristics of the exhibits and how they become entangled with each other to coproduce situated ideas about evolution among visitors (Ceder, 2021; Moser, 2010).

As we alluded to in the 'Introduction' section, archaeology has not always been objective on the subjects of gender and ethnicity. Rather, archaeology seems to have constructed early hominids in terms of stereotypic andro- and Eurocentric notions of ethnicity and gender that categorise individuals as unambiguously female or male, position female individuals as passive and submissive (Brightman, 1996; Conkey \& Spector, 1984), and marginalise non-European identities as being archaic, 'other', and of lesser value (Athreya \& Ackermann, 2020). These culturally specific modes of representation intersect with each other and with other stereotypic notions, for instance of age and social usefulness (GiffordGonzalez, 1993). In our analysis of the three hominid exhibits in The Human Journey, we thus attempt to systematically characterise each hominid representation in terms of a series of dualisms that we have identified in previous research and that symbolise the archaic and primitive vs. the modern and advanced and/or inferiority or lesser value vs. superiority or greater value. These dualisms include ape-like features vs. human-like features (Athreya \& Ackermann, 2020; Scott, 2007; Wiber, 1994), hairiness vs. hairlessness (Moser, 1992; Wiber, 1994), dark skin vs. pale skin (Lutz \& Collins, 1993; Pillay, 2010; Wiber, 1994), crude or no tool use vs. sophisticated tool use (Athreya, 2018; Brightman, 1996; GiffordGonzalez, 1993), crouching/sitting position vs. standing (Gifford-Gonzalez, 1993), and passive vs. active (Gifford-Gonzalez, 1993; Wiber, 1997). In this way, our a priori analysis of the three hominid exhibits prepares us for the investigation of learners' meaning making because it sensitises us to the presence and absence of key themes about gender and ethnicity in the exhibition.

\subsection{The Educational Activity}

The data provided for the study comes from a videotaped activity of an educational program of the Swedish Museum of Natural History developed by the museum educators (Edvall \& Ek, 2008). In this activity, visiting school classes explore selected exhibits of the museum exhibitions in small groups of students. At the beginning of the activity, the student groups are asked to study each exhibit for a few minutes and write down questions elicited by the exhibit. After that, each group discusses its questions for ten to fifteen minutes. During the activity, the exhibit texts are hidden and many ideas and interpretations about what is displayed arise in the conversation. In the last part of the activity, each group gives an account of their observations and questions for the rest of the class. During this presentation, the questions elicited by the exhibit are re-examined and discussed with the museum educator. The activity is inspired by pedagogical approaches used in museums of 
art (Housen, 2001); however, in the activity developed in the Swedish Museum of Natural History, the students' own questions are the starting point and the pivotal element for the development of the conversation.

In the present study, groups of students were observed as they participated in the museum activity described above, exploring the hominid exhibits in the exhibition The Human Journey (Fig. 2). The groups come from six different lower and upper secondary school classes in Stockholm who visited the museum on different occasions. For all these visiting classes, evolution was a central component in the Swedish curriculum. In lower secondary school, evolution is taught as a part of the subject Biology; at the upper secondary level, evolution is studied within the core subject Science Studies or Biology (The Swedish Agency for Education, 2018a; 2018b). In the beginning of the activity, the classes were organised in smaller groups of two to three to explore the exhibits. Then, three groups from each class were randomly chosen and asked to participate in the study. In total, 33 students ( 21 boys and 12 girls) distributed in fifteen groups agreed to participate in the study (nine groups with only boys, three groups with only girls, and three mixed groups), reflecting the moderate overrepresentation of male students in the visiting classes. Ten out of the fifteen groups belonged to the upper secondary school (22 students, age 16 to 18 years) and five groups belonged to the last year of the lower secondary school (11 students, age 15 to 16 years). As the unit of analysis in this study is the talk in the group, we do not further consider the gender composition of the groups. The students' talk in the groups was audiorecorded individually with voice recorders. Additionally, in order to follow the dynamics of the discussions (i.e. gestures and other interactions between the students and the exhibits), a video recorder was placed near each exhibit. Each group spent 30-40 min in the discussions of the three hominid exhibits. The students' talk was transcribed verbatim and translated from Swedish into English with as few changes as possible from the original phrasing. The study followed the Swedish Research Council's rules and guidelines for research, regarding information, consent, confidentiality, and utilization of research data (Swedish Research Council, 2017). To ensure anonymity, fictitious names are used for all participants in the reported data.

\subsection{Analysis of Students' Meaning Making}

We analysed the students' meaning making using practical epistemology analysis, a theoretical mechanism for studying learning as a discursive meaning making process (Kelly et al., 2012; Wickman, 2004). Four analytical concepts are central in practical epistemology analysis: encounter, gap, relations, and stand fast. Encounters occur between persons and between persons and artefacts or natural phenomena. As an activity proceeds, the participants notice gaps as a result of such encounters. To fill a gap, participants establish relations to those things which they are already familiar with, and which they do not need to put into question for the moment. These are the things which stand fast in the particular situation. Usually, that which stands fast is seen through those words which are used by interlocutors without questioning.

To exemplify the use of these analytical concepts, we present here a short fragment of the conversation between Anna and Lisa when they approach the exhibit of Homo ergaster, after visiting the exhibit of Homo neanderthalensis. 


\begin{tabular}{ll}
\hline Lisa & I think so...I think that is more... \\
Anna & I believe that depends on the climate... where it is. The warmer the \\
& country is, the less hair you need \\
Lisa & I thought so too. When it's colder they need more to protect themselves \\
Anna & Mm...it should be like dogs, now \\
\hline
\end{tabular}

The encounter in this situation is with the model and the surrounding environments represented in the exhibit. As a result of this encounter, a gap is noticed by Anna (' $\mathrm{I}$ just wonder how the hair stops growing... in one generation'). The implicit question in this gap concerns the absence of body hair in the model of Homo ergaster compared with the previous visited models. To fill this gap, the students establish relations to those things which they are familiar with and they do not need to put in question at the moment (words that stand fast). Thus, Anna establishes a relation between body hair and climate ('I believe that depends on the climate... where it is'; 'The warmer the country is, the less hair you need'); meanwhile, Lisa establishes a relation between body hair and cold protection ('when it is colder, they need more [hair] to protect themselves'). Finally, Anna establishes a relation to another species that shows the same kind of adaptation ('It should be like dogs, now'). Here, the analysis clearly demonstrates how the students are able to establish relations to their previous knowledge and experiences in order to fill an initial gap; in other words, they are able to make meaning in the encounter with the exhibit. It is important to point out that the four concepts of the practical epistemology analysis are analytical and do not constitute claims about what the participants 'really' think or understand. The practical epistemology analysis is a description of learning made first from the point of view of the learners, that is what they count as sufficient for proceeding in a certain direction (Wickman, 2004), but that it does not necessarily say anything about the relevance for what it is learned as accepted scientific knowledge. A subsequent analysis is needed to assess the relevance or the quality of these learning actions and, in the present study, we performed this analysis by comparing the gaps and relations in encounters with the analysis of the hominids exhibits. For instance, in the conversation between Anna and Lisa, noticing the first gap ('I just wonder how the hair stops growing...in one generation') in the transition between two exhibits could be interpreted as the learners perceiving human evolution as a linear process in which changes occur at individual rather than at population level.

In the transcriptions of students' conversations, we specifically searched for instances where the students notice gaps or established relations related to aspects of ethnicity and gender. We use here the concepts of ethnicity and gender in a broader sense. Thus, gaps related to ethnicity embrace classical notions of 'race' such as the skin colour ('they are whites', 'their skin is black'), ethnical groups ('he is a typical African', 'they are Europeans'), or national groups and countries ('these evolved in Germany'). Gaps and relations related to gender were identified in encounters when the students noticed biological, cultural, or social aspects of sex. Biological aspects of sex were, for instance when the students perceived sexual dimorphism between the male and male models of hominids ('He is larger than her', 'The girl has got breasts'). Gaps related to cultural or social aspects of sex were identified when the students noticed external attributes ('the women, are long-haired compared to the man'), artefacts ('did both the man and the woman use those tools?'), or roles ('he is a hunter') in the reconstructions of the female and male hominids. 


\section{Findings}

In the following, we first present the analysis of the hominid exhibits in The Human Journey. We then present our analysis of learners' meaning making in The Human Journey, focusing on their interactions with the three hominid exhibits and each other.

\subsection{Ethnicity and Gender in the Hominid Exhibits in The Human Journey}

The exhibition The Human Journey is physically located in continuation of the exhibition 4.5 Billion Years: The History of Earth and Life, which presents the origin and evolution of life on Earth. Its introductory text establishes A Human Journey as a systematic, chronological 'journey through space and time, following the course of human evolution over the past 7 million years', and the exhibition's three pathways have a clear directional flow towards the exit. Together, these features support an overarching narrative of linear progression often found in evolution exhibitions (Ågren, 1995; Ceder, 2021; Scott, 2007).

Where the main pathway of The Human Journey begins is found the Australopithecus afarensis exhibit (Fig. 2A). The two hyperrealistic Australopithecus afarensis reconstructions have relatively long arms and short legs, and in accordance with palaeontological research findings, they are dark-skinned and hirsute (Jablonski, 2012). Their faces are apelike in that they have protruding brows, and lack chins. Both walk bipedally, in the direction of the exhibition's chronology. The larger individual, depicted with male sex characteristics (penis, broader shoulders), walks behind the smaller individual, depicted with female sex characteristics (breasts, narrower shoulders). The substantial size difference thus conferred on the sexes of Australopithecus afarensis is not based in conclusive evidence (Zihlman, 1997); in fact, the sexual dimorphism of Australopithecus afarensis was probably comparable to that of modern humans (Reno et al., 2003). Finally, the positioning of the two individuals is based on the fossilised footprints of two Australopithecus afarensis, left in volcanic ash in Tanzania (Swedish Museum of Natural History, 2020a), even though there is not general agreement among palaeontologists that they signify an association between the two individuals that left them (Zihlman, 1997; Wiber, 1997). However, the effect of the positioning of the two individuals conveys the idea of a familiar nuclear family, even though there is scant evidence of this particular social grouping among human ancestors (cf. Zihlman, 1997; Gifford-Gonzalez, 1993).

The main path of the exhibition leads on from Australopithecus afarensis to Homo ergaster. The hyperrealistic Homo ergaster model stands in front of a skeleton that has been reconstructed from fossil evidence found near Lake Turkana in Kenya (Swedish Museum of Natural History, 2020a); both face in the direction of 'evolutionary progression' (Fig. 2B). The Homo ergaster model is relatively tall and slender, and has dark, hairless skin in accordance with palaeontological research findings (Jablonski \& Chaplin, 2006; Manning, 2020). Several technologies are in evidence, as the reconstructed Homo ergaster wears a loincloth and carries a hand axe. Even so, palaeontological research indicates that clothing only appeared much later in human evolution (Toups et al., 2010), while tool use may have appeared as early as with the Australopithecines (Susman, 1994). The representation of Homo ergaster reinforces the association between maleness and technology because it shows a male specimen holding a tool, but no female, with or without tools (cf. Brightman, 1996; Gifford-Gonzalez, 1993). Furthermore, it reinforces the perception 
of Homo ergaster as more advanced than Australopithecus afarensis, although the technologies in question cannot be definitely attributed to Homo ergaster.

Finally, the main path of The Human Journey leads to the Homo neanderthalensis exhibit. Like the other hominids, two of the Homo neanderthalensis individuals are walking in the direction of the main pathway, thus supporting the notion of a linear progression 'out of Africa' towards Europe. The reconstructed individuals are light-skinned and have advanced hunting technologies as evidenced by the prey they carry, thus further supporting the notion that humanity emerged in Europe, as a result of the migration away from its origins (cf. Ceder, 2021; Scott, 2007). The reconstructed female individual has female sex characteristics (breasts) and long hair, and is carrying a brace of smaller prey animals. She is standing close to the infant who is sitting on the ground. These details reinforce stereotypical notions of the sexual division of hunting labour described by Brightman (1996), which position female hominids as physically weak and immobilised by caring for children. In contrast, the male individual is carrying a large prey animal on his shoulders, establishing him as the provider of large game. The infant is depicted in a passive, lowered posture, signifying its position in a hierarchical nuclear family constellation (cf. GiffordGonzalez, 1993).

In summary, the three hominid exhibits depict a linear evolutionary progression from the archaic, dark-skinned African to the advanced, light-skinned European, 'reducing the complexity of the fossil record and human diversity to a neat procession of species' (Scott, 2007, p. 35). Furthermore, the prioritising of the male reconstructions (four individuals, present in all three exhibits) over females (two individuals, present in two of three exhibits) and infants (one individual, present in one exhibit), together with the relative positioning, postures, and activities of the hominids, associate maleness with primacy, technology, and strength, and femaleness with nurturing and subordination (Wiber, 1997). In other words, we find The Human Journey to reproduce a number of the gendered and raced stereotypes that link the adult, white, male Euro-American with evolutionary progress and superiority (cf. Athreya \& Ackermann, 2020; Ceder, 2021; Conkey \& Spector, 1984; Scott, 2007; Zihlman, 1997).

Finally, it is worth noting that The Human Journey includes three additional hominid dioramas (see Fig. 1); one with a dark-skinned, hirsute female Homo habilis holding a stone tool, one with a dark-skinned, hirsute male Homo floresiensis, and finally, one with a light-skinned male Homo sapiens with sophisticated clothes and hunting tools. These three dioramas were not part of the museum activity described here; even so, their relative sequence, position, and gender/ethnic characteristics tend to support our assessment of the exhibition as reproducing a stereotypical and linear 'out of Africa' narrative of human evolution.

Table 1 Number of instances where students noticed aspects related to gender or ethnicity, across the three hominid exhibits

\begin{tabular}{llll}
\hline & $\begin{array}{l}\text { Australopithecus } \\
\text { afarensis }\end{array}$ & Homo ergaster & $\begin{array}{l}\text { Homo } \\
\text { neander- } \\
\text { thalensis }\end{array}$ \\
\hline \# ethnicity & 8 & 12 & 11 \\
\# gender & 30 & 10 & 20 \\
\hline
\end{tabular}




\subsection{Learners' Meaning Making at the Hominid Exhibits}

In the analysis of the conversations, we found a total of 91 instances where the students noticed aspects related to ethnicity or gender, the latter almost twice as often (Table 1). Mentions of ethnicity were distributed rather evenly among the three exhibits, while gender aspects were more frequently noticed by the students at the Australopithecus afarensis and Homo neanderthalensis exhibits - the two exhibits displaying both male and female individuals - than at Homo ergaster (chi-square, $p<0.05$ ). Ethnicity was mentioned in 10 groups out of the 15 groups that participated in the study, while gender was mentioned in 14 out of the 15 groups.

The practical epistemology analysis of students' conversations shows that, in the encounter with the three hominid exhibits, discussions of ethnicity and gender contributed significantly to students' meaning making processes. However, we found an important qualitative difference in the patterns of mentioning ethnicity and gender: The relations established by the students when they discussed aspects of ethnicity suggest a rather uncritical perception of the exhibits' messaging, whereas when they talked about gender, the students' reasoning demonstrated a more critical stance on the messages communicated in the exhibits, and at times, questioned their trustworthiness. In the following sections, we provide detailed examples of the processes of meaning making from students' conversations.

\subsubsection{Ethnicity}

Discussions of ethnicity were frequently initiated by the students when they noticed the darker colour of the skin of the models of Australopithecus afarensis (Excerpt 1) and Homo ergaster (Excerpt 2). In the process of meaning making, the students often filled this gap with relations to Africa.

Excerpt 1.

\begin{tabular}{lll}
\hline 1 & Eva & Their skin color...in fact, they are black \\
2 & Liv & Yes \\
3 & Eva & $\begin{array}{c}\text { They are in Africa. They are still in Africa, sticking } \\
\text { around, basically naked. The questions is... when } \\
\text { did these people leave Africa? }\end{array}$ \\
& Lood question! I don't know. These look like... \\
5 & Eva & Yeah, this is a 'proto-ape', sort of \\
6 & Liv & They emigrate, so to say \\
\hline
\end{tabular}

Excerpt 2.

$\begin{array}{lll}7 & \text { Lisa } & \text { I think that you can see where he comes from. He is dark skinned....and the hair, you know... } \\ 8 & \text { Erik } & \text { Africa }\end{array}$

However, in other instances, ethnicity is noted as a geographical element or an identity before skin colour is mentioned. In the following excerpts, 'Africa' (or 'African') is uttered first, and relations are then established to the colour of the skin and other features of the species that suggest a more ape-like morphology (Australopithecus afarensis, Excerpt 3,) or stereotypes (Homo ergaster, Excerpt 4). 
Excerpt 3.

\begin{tabular}{lll}
\hline 9 & Peter & This is Africa, isn't it? \\
10 & Anders & $\begin{array}{c}\text { Right. They just began to walk. They got real } \\
\text { hands and feet, so to say }\end{array}$ \\
11 & Peter & They look like a bit ape. They have huge long arms \\
12 & Anders & Yes, the arms are down to almost the knees \\
\hline
\end{tabular}

\section{Excerpt 4.}

\begin{tabular}{lll}
\hline 13 & Gela & May I say something? I think that he is a typical African \\
14 & Anna & More like a South American, I would say \\
15 & Gela & $\begin{array}{c}\text { Yes, but some African men are like him, I mean, rather } \\
\text { short, dark skinned...not fat... }\end{array}$ \\
16 & Nahbi & Broader? \\
17 & Roisin & Muscular! \\
18 & Gela & Of course, they are. But not fat, they live in the savannah \\
\hline
\end{tabular}

In several instances, when aspects of ethnicity were noticed in the encounter with models of Australopithecus afarensis, the relations in the process of meaning making suggested that students perceive these individuals as actively emigrating or leaving Africa (Excerpt 1, turn 3; Excerpt 5, turn 20 and Excerpt 6, turn 24).

\section{Excerpt 5.}

19 Filip We are from Africa, originally

20 Max Right, but those...we will see where they emigrating. If they are in the Arabic countries or...not here in the North, of course

\section{Excerpt 6.}

\begin{tabular}{lll}
\hline 21 & Sara & What kind of environment did they live? It looks like a forest \\
22 & Lisa & I think it is Africa, I mean...the very origin is from there \\
23 & Sara & Yes, but I can't imagine how they could survive in a colder climate if... \\
24 & Lisa & $\begin{array}{c}\text { Yes, they may have got a bit on the road, and so I think if they were } \\
\text { native to Africa and they kind of start to move }\end{array}$ \\
\hline
\end{tabular}

We observe how dark skin, warm climate, and ape-like morphological features are associated with Africa. In contrast, when the students noticed the lighter skin and blue eyes represented in the models of Homo neanderthalensis, they frequently established relations to Europe, 'the North' or Germany (Excerpts 7 and 8).

Excerpt 7.

25 Eva Exhibit three [Homo neanderthalensis]. Two adults and a child, and they have become white

26 Liv That struck me, too

27 Eva The girl is not so hairy, but the guy has got some hair on the upper body [...]

28 Liv Well ... probably because these evolved in Germany, or wherever it is. Eh...somewhere northerly

29 Eva [...] I wonder when did they become white? They are blue-eyed too, that's interesting! 
30 Liv Yes, because it is a mutation, I mean blue eyes is a mutation, if I am not mistaken...or was it green eyes?

31 Eva Both blue eyes and green eyes are mutations

It is interesting to note that in the instances when students noticed aspects of ethnicity in Homo neanderthalensis, they established relations expressing the idea of development or evolution, e.g. the hominids 'become' white and blue-eyed through mutations (Excerpt 7, turn 25, turn 29). This idea of development or progression relative to the earlier hominids found in Africa was exemplified when one of the students noticed a gap related to the presence of tools in the Homo neanderthalensis exhibit (Mats: 'Wow! They use more tools than the Africa-man').

Excerpt 8.

32 Elias Yes, now we are up in Europe. Are those races or species? What do you think?

33 Samuel They are human beings. It's a species, isn't it?

34 Elias The preys, it is obvious that they began to catch a little more mobile prey. Now, they have to...well you can see the gearing ...they have invented tools

35 Samuel I noticed the traps too. Birds are rather difficult to catch if you don't have bows. Did they begin making snares?

36 Elias Probably. I think that they just developed things so they could catch more animals

In another example, when the students noted Europe as the origin of Homo neanderthalensis, the gap was filled with relations that recognise these hominids as belonging to the species of 'human beings' (Excerpt 8, turn, 33). In the same dialogue, the idea of higher development was also evidenced when Elias noticed the presence of preys in this exhibit. Here, the gap was filled with several relations that suggest new acquired abilities in Homo neanderthalensis, such as hunting mobile animals, inventing tools (Turns 34, 35), and developing objects (Turn 36).

\subsubsection{Gender}

Gender mentions were present to a large extent in the students' conversations in a variety of situations. At the exhibits that contained both female and male individuals (Australopithecus afarensis and Homo neanderthalensis), gaps occurred frequently when the students explicitly mentioned the different sexes (Imre: 'These are a man and woman', Australopithecus afarensis), differences in body sizes (Lucas: 'The difference in size between the man and the woman is not so big', Homo neanderthalensis compared to Australopithecus afarensis), or body features that were immediately related to different sexes (Excerpt 9).

Excerpt 9.

37 Eva Their breasts are basically of the same size, in relation to each other [male and female], anyway, that has changed...

38 Liv You mean the chest?

39 Eva No, I mean 'tits', 'boobs'... so, they are basically the same size. It is mostly fat, but there are 'man-boobs' too

40 Liv Yeah! [chuckles] I wonder why humans have breasts, when other animal species don't? Dogs for instance, when they are just at the end of their gestation periods... then their breasts grow, but why do we have breasts during all our lives, so to speak? 
The dialogue between Eva and Liv exemplifies the process of meaning making found frequently in students' discussions of gender. In the encounter with the two Australopithecus afarensis individuals, Eva (Turn 37) notices a gap (the female and male have breasts of similar size), which is filled in the following dialogue with relations to students' own experiences and observations (Turns 39-40). Among these relations, we observe elaborated reasoning about evolutionary biology, grounded in the student's previous knowledge, which creates a new gap in the process of meaning making (why do women have breasts their entire life? Turn 40).

Among the 60 instances related to gender aspects, we identified 19 in which the students adopted a more critical stance towards the message presented in the exhibits. In these instances, their meaning making mainly revolved around two different lines of reasoning: First, they reason that the models of the hominids may have been partially constructed on assumptions where the scientific evidence is not sufficiently robust. Second, they reason that the representations reflect stereotypical notions about the lifestyle and gender patterns of actual humans. An example of the first process of meaning making occurred when Agnes noticed that the female Homo neanderthalensis had longer hair than the male (Excerpt 10, turn 41).

Excerpt 10.

\begin{tabular}{|c|c|c|}
\hline 41 & Agnes & The women are long-haired compared to the men \\
\hline 42 & Mia & Yes, I don't know if it's like today \\
\hline 43 & Agnes & Did they start with that already? \\
\hline 44 & Mia & $\begin{array}{l}\text { I don't know... who knows? They just found the } \\
\text { skeleton. Can the hair be preserved in some } \\
\text { way? }\end{array}$ \\
\hline 45 & Agnes & $\begin{array}{l}\text { Maybe the researchers know, but I don't think so. } \\
\text { That happened a very long time ago }\end{array}$ \\
\hline 46 & Mia & Yes, maybe they just assume it \\
\hline
\end{tabular}

In the relations established to fill this gap, the students reflected that this difference between sexes seems to be more consistent with modern customs (Turns 42-43). They then concluded that, even though this depiction may not be supported by fossil evidence (Turn 44), researchers may make assumptions in scientific representations (Turns 45-46).

An example of the second process of meaning making is demonstrated by the conversation between two students at the Australopithecus afarensis exhibit. In the encounter, Josef noticed the significant size difference between the sexes (Turn 47) and, to fill this gap, he established relations to hunting, speed, and violent male behaviour. Using a manifest ironical tone, Mats suggested that the representations of Homo neanderthalensis were a stereotypical reflection of modern traditional gender roles (Turn 50).

Excerpt 11.

Josef
Mats

Josef

Mats

Josef
Why this huge difference in size? I don't know... maybe it has something to do with men...they need to be larger because...eh, they hunt

Exactly

They deal with violence. The have to run fast...so maybe... It's just like now! The woman is at home in the kitchen and the man is out getting some food! [ironically]

Almost the same...[ironically] 
A critical stance towards gender representations was also in evidence when the students reflected, implicitly or explicitly, on the purpose of the exhibits. Thus, on several occasions, the students discussed how the differences between the sexes in the models could be an artefact, a product of curatorial intentions, rather than a real representation of the past. An example of this reasoning is provided in the following dialogue between Eva and Liv (Excerpt 12). When they explored the exhibits with Homo neanderthalensis, they noticed the relative difference of breast size with the models of Austrolopithecus afarensis (Turn 52). Then, they established relations to possible evolutionary processes (Turn 53-54) but also expressed the possibility of that the difference could be explained by 'the reconstruction' itself (Turn 54). Later on, when they recalled the long-haired woman, Eva explicitly articulated the idea of curatorial intention ('the reconstructor') to explain the differences between sexes (Turn 56).

Excerpt 12.

52 Eva The girl has got breasts, big breasts, compared with the first exhibit [Australopithecus afarensis]. It's a long time between them. That's interesting

53 Liv Yeah. There are differences between men and women. Have these differences increased?

54 Eva Or decreased, because now they are about the same size [Homo neanderthalensis], but once again, the question is if this is about the reconstruction or...

55 Liv ...or if it was so

$[\ldots]$

56 Eva The long hair of the woman... could it be something that the 'reconstructor' does to clarify that that is a girl and that is a guy, for us? Or it may have been like this, from the beginning?

Interestingly, a critical stance towards curatorial intentions were not only related to differences between the sexes, but also to the absence of a female model in the Homo ergaster exhibit (Excerpt 13, Turn 57; Excerpt 14, Turn 60).

Excerpt 13.

\begin{tabular}{|c|c|c|}
\hline 57 & Max & $\begin{array}{l}\text { Have you thought that they didn't dare } \\
\text { to put a woman in there? }\end{array}$ \\
\hline 58 & Filip & What? \\
\hline 59 & Max & Maybe, it is considered too offensive... \\
\hline
\end{tabular}

Excerpt 14.

\begin{tabular}{|c|c|c|}
\hline 60 & Alex & $\begin{array}{l}\text { They probably went around naked too, it was probably not like today. There's some- } \\
\text { thing a bit weird... There isn't any female sculpture there... It would be interesting to } \\
\text { see what females, or women, looked like }\end{array}$ \\
\hline 61 & Lucas & It's a bit of discrimination \\
\hline 62 & Alex & It feels like, you want to see if there was some size difference between men and women \\
\hline 63 & Lucas & Maybe there wasn't any difference \\
\hline 64 & Alex & Eh...no...maybe \\
\hline 65 & Lucas & Maybe that's a girl...who knows? \\
\hline 66 & Alex & [...] Should it be called female or woman? \\
\hline 67 & Lucas & [Expletive], it's a question of interpretation. Not a female though \\
\hline
\end{tabular}

In the dialogue between Max and Filip, the non-inclusion of a female in the exhibit is interpreted in terms of curatorial concern about visitors' susceptibility (Turn 59). 
In the conversation between Lukas and Alex, the relation established to fill this gap clearly concerned not only discrimination in the values and norms behind the production of the exhibit, but also the possibility of different interpretations behind the perceived androgynous representation of Homo ergaster (Turn 67).

In summary, the gendered and raced stereotypes in the exhibition The Human Journey were noted and discussed by the students in this study. The stereotypes related to ethnicity were largely accepted as scientific fact by the students. In contrast, the gender stereotypes were more often critiqued by the students, who questioned curatorial intent and the availability of scientific evidence. In the final sections, we discuss these findings and their implications for exhibit design and evolution education. Along the way, we offer our responses to the questions posed in the Call for papers (2021): If science is inherently oppressive (i.e. sexist, racist, imperial), how can it be salvaged from its exploitative nature and legacy? How can learning environments be designed to foster understanding of how science should work?

\section{Discussion}

Our study confirms the important role of natural history museum exhibits as resources for learning (Ash, 2004) and demonstrates the potential of designing activities that support exploration and dialogue between learners (Allen, 2004; Davidsson \& Jakobsson, 2012; Rennie, 2014). Specifically, in the activity studied here, students' interactions with the hominid exhibits, and with each other, clearly afforded their processes of making meaning of human evolution: Details of hominid morphology, posture, and activity were noticed by the students and used to establish relations to their previous experience and knowledge as well as concepts and ideas from school science, including evolution theory. We thus reiterate the point we made in the introduction, namely that natural history museums are uniquely positioned to contribute to evolution education (Diamond \& Evans, 2007; King $\&$ Achiam, 2017). However, our study also demonstrates that in spite of museums' public image of trustworthiness and impartiality (Britain Thinks, 2013; Museums Association, 2013), they do not always provide the public with unbiased or culture-free science. Indeed, in the present case, we have shown how the 'othering' of African identities and of women that is found in western socio-political agendas and western science (cf. Athreya \& Ackermann, 2020) has seemingly influenced the narrative created by the designers of The Human Journey.

\subsection{Encoding and Decoding of Ethnicity and Gender in Exhibits}

In this study, we saw that when students encountered the hyperrealistic hominid reconstructions in The Human Journey, they effortlessly decoded their details (cf. Gifford-Gonzalez, 1993; Levin, 2010), including details of gender and ethnicity. As mentioned in the 'Methods' section, this ease of decoding is part of the attraction of hyperrealistic models for museums, who sometimes struggle to encode clear scientific messages in exhibit design. However, hyperrealism also entails certain risks. According to archaeologist Stephanie Moser, artistic representations like the hominid reconstructions are 'part of the knowledge cycle, and not outside it' (cited in Balter, 2009, p. 137), meaning that reconstructions affect how scientists - and members of the public_-build knowledge about hominids and their 
behaviour. In the present study, we observed this most clearly when students noted ethnicity-related aspects of the hominids and in many cases, unquestioningly reproduced the 'out of Africa' narrative of human evolution (cf. Scott, 2007), in which ape-like hominids with more 'primitive' bodies, darker skin, and lacking technology move away from their origins in Africa and gradually evolve into light skinned, blue-eyed, and technologically advanced hominids associated with Europe. In fact, in our analysis, we did not find any examples of students challenging the reconstruction of the hominids' skin colour or the implicit dualism between the primitive in Africa versus the advanced in Europe implicitly represented in the exhibition. At this moment in time, where museums are challenged to justify themselves in the face of calls for decolonisation, inclusion, and sustainability (Evans et al., 2020), exhibit designs that promote ethnical stereotypes seem fraught with trouble, even if those effects are unintentional.

In contrast to the ethnicity-related aspects of the hominid exhibits, the gender-related aspects of the exhibits gave rise to more critical stances among the students, especially when the exhibits included reconstructions of both female and male hominids (Australopithecus afarensis and Homo neanderthalensis). Even though the obvious morphological differences between female and male reconstructions were often the point of departure for conversations about sex and gender, other observations occurred that reflected more nuanced and in-depth interpretations of the reconstructed scenes, for instance of the relatively submissive role of the female Homo neanderthalensis in relation to the stereotypical 'Man-the-Hunter' depiction of the male (cf. Conkey \& Spector, 1984; Gifford-Gonzalez, 1993). Across the data, students challenged the scientific trustworthiness and the pedagogical intentions of the exhibits, indicating they perceived the exhibits as being biased, founded on present-day gender roles and norms, or even inequitable and discriminatory.

In a sense, students' critique of the stereotypical gender roles embodied in the hyperrealistic hominid reconstructions is positive. It is an indication that the students require a broader range of perspectives, a wider array of actors, and more well-founded aesthetic challenges to think about the past and what it means to be human (Gifford-Gonzalez, 1993); in other words, they are requesting what Levin (2010) refers to as queering the exhibits (we note that this queering process could entail representing hominids in more genderfluid ways, although we did not observe instances of students specifically mentioning this). In doing so, the students implicitly call for an acknowledgment of how our knowledge about human evolution develops, alongside the story of human evolution itself (Levin, 2010).

\subsection{Salvaging Evolution Education}

As discussed, the representations of human evolution in the exhibition offer a somewhat 'racist and sexist' vision of science. Even so, our findings also hint at answers to the questions posed in the Call for papers (2021). First, we would argue that if representations of ethnicity are seemingly accepted by museum visitors as authoritative scientific facts, it falls upon scientists, curators, and artists involved in exhibit design to provide visual representations of human evolution that are free from stereotypical views and prejudices. Fortunately, there are signs that museums are addressing this challenge. In fact, in The Human Journey, museum professionals carried out a major revision of the scientific content in 2020, with important consequences for the visual representations of the hominids. Specifically, the hominids' skin colour can now be changed virtually by museum visitors in animations in adjacent touch screens (Swedish Museum of Natural History, 2020b). This modification was not only the product of a public debate about ethnicity, but also a consequence 
of cutting-edge palaeontological research using ancient DNA, showing that Western European populations of modern humans probably had dark skin (National History Museum, 2018). This initiative may help establish the point that skin colour cannot be used as a characteristic for categorising humans into race, but has evolved independently multiple times in human evolution (cf. Jablonski \& Chapling, 2017). More generally, it also offers a partial answer to the question of how learning environments can be designed to foster understanding of how science should work, because it exemplifies a way to salvage oppressive science 'from its exploitative nature and legacy' (Call for papers, 2021). We acknowledge that vastly more effort is needed to address the persistent 'out of Africa' narrative of human evolution (Athreya \& Ackermann, 2020), but we see the initiative of the Swedish Museum of Natural History as an important step.

Our second response to the question of designing learning environments to foster understanding of how science works takes a point of departure in the gendered stereotypes in The Human Journey. As described, we observed how students had an awareness of the sexist vision of human evolution communicated by the exhibition. Even though considering gender issues should be fundamental in the design of learning environments (cf. Nicolaisen \& Achiam, 2020; Silfver, 2019), we also see a constructive potential in the critical stances and problematising capacity demonstrated by the students. We suggest that this capacity could be used as a resource in teaching activities that scrutinise stereotypical notions of gender and relations of power in science, ultimately creating an awareness that science is subject to the same socio-political, cultural, disciplinary, institutional, historical (etc.) influences as any other human activity. This could be achieved by designing teaching activities in museums that explicitly analyse the content of science exhibitions against their socio-cultural, disciplinary and historical context, in a similar vein to for instance Karen Wonders' (2003) careful analysis of the nationalistic messages embedded in biological dioramas. This attention to science as a way of knowing, and to how it connects to other ways of knowing, could promote exploration and discussions of issues and experiences that grab the interest of young learners (Anderson, 2007).

In the present activity, personal experiences and knowledge of their own bodies can explain students' interest in gender aspects as manifested in their conversations. This finding agrees with previous studies that indicate the importance of bodily experiences to learn about bodies, biologically as well as in terms of values (Orlander \& Wickman, 2011). However, it was for us surprising that the students questioned and challenged gender stereotypes to such an extent during the museum activity, as previous studies in Swedish contexts show that stereotypical gender identities and performances are often maintained in science and technology education (Orlander et al., 2015; Silfver, 2019). On the other hand, a previous study in out-of-school settings by Anton Puvirajah, Geeta Verma, and Horace Webb (2012) suggests that the museum context may play an important role in promoting student ownership and agency and creating a space for authentic and meaningful science learning. Puvirajah et al. (2012) suggest that the context of the activity in their study-a robotic competition in convention centres-made possible discourse practices that were different from students' classroom experiences in that they were descriptive, relational, explanatory, and had an authentic evaluative dimension. Similar arguments suggest the need to study how teaching in an out-of-school setting may contribute to challenging stereotyped power relations (Rennie et al., 2003).

Finally, the present study is limited to a specific museum exhibition about human evolution, and a specific set of data on visitors' interactions. Even so, our findings show that this specific educational activity developed at the Swedish Museum of Natural History may have consequences for evolution education more generally and in the science classroom. 
Traditionally, teaching about the theory of evolution in school settings have focused on students' understanding of the concepts of natural selection and adaptation, as well as how variation occurs in a population (Bishop \& Anderson, 1990; Gregory, 2009; Thagard \& Findlay, 2010). In the museum environment, the teaching activity and the exhibition provided the students with opportunities to discuss authentic questions and explore issues, enriching their views about evolutionary processes. An example of authentic questions that emerged from the students' discussions is given by the dialogue between Eva and Liv (Excerpt 9) which clearly reflects the complexity behind explanations in evolution theory: explanations that involve relationships between adaptations, constraints, and historical processes where an organism must be understood as an integrated whole (Gould \& Lewontin, 1979). Furthermore, our findings demonstrate how the activity in The Human Journey prompted interesting discussions about the limitations of scientific knowledge. Questions as "How do scientists know'?"(Excerpt 10) and other instances of discussions where students questioned gender aspects in the exhibits are evidence that students' meaning making revolved around central aspects of nature of science (Lederman, 2007). These questions were subsequently discussed with the museum educator and the students had the opportunity to confront their own ideas about the nature of scientific knowledge. Similar arguments in favour of the use of 'hands-on' activities have frequently been recommended as a way to improve students' understandings of the nature of science (Lederman, 2007). Thus, from our findings, we suggest that evolution education in the classroom could be enriched with content and representations that diversify historical processes of both evolutionary changes and knowledge production (cf. Ceder, 2021) as well as explorative activities that engage students in authentic questions about our evolutionary path.

Author Contribution Not applicable.

Funding Open access funding provided by Stockholm University. This study was supported by the Swedish Arts Council.

Availability of Data and Material (Data Transparency) Not applicable.

Code Availability (Software Application or Custom Code) Not applicable.

\section{Declarations}

Additional Declarations for Articles in Life Science Journals that Report the Results of Studies Involving Humans and/or Animals Not applicable.

Ethics Approval (Include Appropriate Approvals or Waivers) Not applicable.

Consent to Participate (Include Appropriate Statements) Not applicable.

Consent for Publication (Include Appropriate Statements) Not applicable.

Conflict of Interest The authors declare that they have no conflict of interest.

Open Access This article is licensed under a Creative Commons Attribution 4.0 International License, which permits use, sharing, adaptation, distribution and reproduction in any medium or format, as long as you give appropriate credit to the original author(s) and the source, provide a link to the Creative Commons licence, and indicate if changes were made. The images or other third party material in this article are included in the article's Creative Commons licence, unless indicated otherwise in a credit line to the material. If material is not included in the article's Creative Commons licence and your intended use is not 
permitted by statutory regulation or exceeds the permitted use, you will need to obtain permission directly from the copyright holder. To view a copy of this licence, visit http://creativecommons.org/licenses/by/4.0/.

\section{References}

Achiam, M., Simony, L., \& Lindow, B. E. K. (2016). Objects prompt authentic scientific activities among learners in a museum programme. International Journal of Science Education, 38(6), 1012-1035. https://doi.org/10.1080/09500693.2016.1178869

Ågren, P. U. (1995). Om museer och utställningsspråk. [On museums and exhibition languages]. Nordisk Museologi, 1, 39-46. https://doi.org/10.5617/nm.3739

Allen, S. (2004). Designs for learning: Studying science museum exhibits that do more than entertain. Science Education, 88(S1), S17-S33. https://doi.org/10.1002/sce.20016

Anderson, R. D. (2007). Teaching the theory of evolution in social, intellectual, and pedagogical context. Science Education, 91(4), 664-677. https://doi.org/10.1002/sce.20204

Ash, D. (2004). How families use questions at dioramas: Ideas for exhibit design. Curator: The Museum Journal, 47(1), 84-100. https://doi.org/10.1111/j.2151-6952.2004.tb00367.x

Ash, D. (2019). Cultural conflict: The stories Dioramas tell and don't tell. In A. Scheersoi \& S. D. Tunnicliffe (Eds.), Natural history Dioramas - Traditional exhibits for current educational themes: Socio-cultural aspects (pp. 113-130). Springer International Publishing. https://doi.org/10.1007/ 978-3-030-00208-4_8

Athreya, S. (2018). Picking a bone with evolutionary essentialism. Anthropology News, 59(5), e55-e60. https://doi.org/10.1111/an.970

Athreya, S., \& Ackermann, R. R. (2020). Colonialism and narratives of human origins in Asia and Africa. In M. Porr \& J. Matthews (Eds.), Interrogating Human Origins (pp. 72-95). Routledge.

Balter, M. (2009). Bringing hominins back to life. Science, 325(5937), 136-139. https://doi.org/10.1126/ science.325_136

Bishop, B. A., \& Anderson, C. W. (1990). Student conceptions of natural selection and its role in evolution. Journal of Research in Science Teaching, 27(5), 415-427. https://doi.org/10.1002/tea.3660270503

Brightman, R. (1996). The sexual division of foraging labor: Biology, taboo, and gender politics. Comparative Studies in Society and History, 38(4), 687-729. http://www.jstor.org/stable/179196

Browning, B. (2015). Transcript of Ken Ham vs Bill Nye debate. http://www.youngearth.org/index.php/archi ves/rmcf-articles/item/21-transcript-ofken-ham-vs-bill-nye-debate

Britain Thinks. (2013). Public perceptions of - and attitudes to - the purposes of museums in society. Museums Association. https://archive-media.museumsassociation.org/05042013-britain-thinks-3.pdf

Call for papers. (2021). Why trust science and science education? Science \& Education. http://www.eshs. org/Call-for-Papers-Science-and-Education-Why-Trust-Science-and-Science-Education.html?lang=en

Ceder, S. (2021). Change at the museum: The knowledge production of human evolution. Reconceptualizing Educational Research Methodology, 12(1). https://doi.org/10.7577/rerm.4243

Conkey, M. W., \& Spector, J. D. (1984). Archaeology and the study of gender. Advances in Archaeological Method and Theory, 7, 1-38. https://www.jstor.org/stable/20170176

Cummins, C. L., Demastes, S. S., \& Hafner, M. S. (1994). Evolution: Biological education's underresearched unifying theme. Journal of Research in Science Teaching, 31(5), 445-448. https://doi.org/ 10.1002/tea.3660310502

Davidsson, E., \& Jakobsson, A. (2012). Understanding interactions at science centers and museums. Sense Publishers.

Davies, P., \& Nicholl, J. (2017). Using object-based learning to understand animal evolution. In M. P. Mueller, D. J. Tippins, \& A. J. Stewart (Eds.), Animals and science education Ethics, curriculum and pedagogy (pp. 145-158). Springer.

Denzin, N. K., \& Lincoln, Y. S. (2005). Introduction: The discipline and practice of qualitative research. In N. K. Denzin \& Y. S. Lincoln (Eds.), Sage Handbook of Qualitative Research (3rd ed., pp. 1-32). Sage.

Diamond, J., \& Evans, E. M. (2007). Museums teach evolution. Evolution, 61(6), 1500-1506. https://doi. org/10.1111/j.1558-5646.2007.00121.x

Diamond, J., \& Scotchmoor, J. (2006). Exhibiting evolution. Museums \& Social Issues, 1(1), 21-48. https:// doi.org/10.1179/msi.2006.1.1.21

Edvall, S., \& Ek, C. (2008). Real learning: Best evidence for the impact of science centres [Poster presentation]. Ecsite Annual Conference, Budapest, Hungary. https://www.ecsite.eu/activities-and-services/ ecsite-events/conferences/2008-ecsite-conference 
Estrup, E., \& Achiam, M. (2019). The potential of palaeontology for science education. Nordina - Nordic Studies in Science Education, 15(1), 97-108. https://doi.org/10.5617/nordina.5253

Evans, H. J., Nicolaisen, L., Tougaard, S., \& Achiam, M. (2020) Perspective. Museums beyond neutrality. Nordisk Museologi, 29(2), 19. https://doi.org/10.5617/nm.8436

Falk, J. H., \& Storksdieck, M. (2009). Science learning in a leisure setting. Journal of Research in Science Teaching. https://doi.org/10.1002/tea.20319

Gifford-Gonzalez, D. (1993). You can hide, but you can't run: Representations of women's work in illustrations of palaeolithic life. Visual Anthropology Review, 9(1), 23-41. https://doi.org/10.1525/var.1993.9. 1.22

Gauchat, G. (2015). The political context of science in the United States: Public acceptance of evidencebased policy and science funding. Social Forces, 94(2), 723-746. https://doi.org/10.1093/sf/sov040

Gould, S. J., \& Lewontin, R. C. (1979). The spandrels of San Marco and the Panglossian paradigm: A critique of the adaptationist programme. Proceedings of the Royal Society of London. Series B, Biological Sciences, 205(1161), 581-598. http://www.jstor.org/stable/77447

Gregory, T. (2009). Understanding natural selection: Essential concepts and common misconceptions. Evolution Education Outreach, 2, 156-175. https://doi.org/10.1007/s12052-009-0128-1

Grimes, L.G. (2012) Teaching evolution: A heuristic study of personal and cultural dissonance [Doctoral dissertation, University of the Pacific]. ProQuest Dissertations Publishing. https://search.proquest.com/ openview/176c3843e3b70e0d490f8a816742a2d0

Groß, J., Kremer, K., \& Arnold, J. (2019). Evolution learning and creationism: Thinking in informal learning environments. In U. Harms \& M. J. Reiss (Eds.), Evolution education re-considered: Understanding what works (pp. 285-305). Springer. https://doi.org/10.1007/978-3-030-14698-6_16

Harms, U., \& Reiss, M. J. (2019). The present status of evolution education. In U. Harms \& M. J. Reiss (Eds.), Evolution education re-considered: Understanding what works (pp. 1-19). Springer International Publishing. https://doi.org/10.1007/978-3-030-14698-6_1

Heddy, B. C., \& Nadelson, L. S. (2012). A global perspective of the variables associated with acceptance of evolution. Evolution: Education and Outreach, 5(3), 412-418. https://doi.org/10.1007/ s12052-012-0423-0

Housen, A. C. (2001). Aesthetic thought, critical thinking and transfer. Arts and Learning Research Journal, $18(1), 99-131$.

Jablonski, N. G., George, C. (2017). The colours of humanity: the evolution of pigmentation in the human lineage. Philosophical Transactions of the Royal Society B: Biological Sciences, 372(1724), 20160349. https://doi.org/10.1098/rstb.2016.0349

Jablonski, N. G. (2012). Skin: Its biology in black and white. Palaeontologia africana, 47, 62-66. https:// core.ac.uk/download/pdf/39675879.pdf

Jablonski, N. G., \& Chaplin, G. (2006). Skin deep. In S. American (Ed.), Evolution: A Scientific American reader (pp. 322-329). University of Chicago Press.

Kelly, G., McDonald, S., \& Wickman, P.-O. (2012). Science learning and epistemology. In B. J. Fraser, K. Tobin, \& C. J. McRobbie (Eds.), Second International Handbook of Science Education (pp. 281-291). Springer. https://doi.org/10.1007/978-1-4020-9041-7_20

Kincheloe, J. L., \& McLaren, P. (2005). Rethinking critical theory and qualitative research. In N. K. Denzin \& Y. S. Lincoln (Eds.), Sage Handbook of Qualitative Research (3rd ed., pp. 303-342). Sage.

King, H., \& Achiam, M. (2017). The case for natural history. Science \& Education, 26(1-2), 125-139. https://doi.org/10.1007/s11191-017-9880-8

Lederman, N. G. (2007). Nature of science: Past, present and future. In S. K. Abell, K. Appleton, \& D. Hanuscin (Eds.), Handbook of Research in Science Education (pp. 831-880). Taylor \& Francis.

Levin, A. K. (2010). Straight talk: Evolution exhibits and the reproduction of heterosexuality. In A. K. Levin (Ed.), Gender, sexuality and museums A Routledge Reader (pp. 375-394). Routledge.

Lutz, C. A., \& Collins, J. L. (1993). Reading national geographic. University of Chicago Press.

Manning, P. (2020). Methods for human history. Studying social, cultural and biological evolution. Palgrave Macmillan. https://doi.org/10.1007/978-3-030-53882-8

Meng, A. P. K. (2004). Making history in from colony to nation: A multimodal analysis of a museum exhibition in Singapore. In K. L. O'Halloran (Ed.), Multimodal discourse analysis: Systemic functional perspectives (pp. 28-54). Continuum.

Moser, S. (1992). The visual language of archaeology: A case study of the Neanderthals. Antiquity, 66(253), 831-844. https://doi.org/10.1017/S0003598X0004477X

Moser, S. (2010). The devil is in the detail: Museum displays and the creation of knowledge. Museum Anthropology, 33(1), 22-32. https://doi.org/10.1111/j.1548-1379.2010.01072.x

Museums Association, (2013). Public perceptions of - and attitudes to - the purposes of museums in society. https://www.museumsassociation.org/download?id=954916 
Nadelson, L. S., \& Hardy, K. K. (2015). Trust in science and scientists and the acceptance of evolution. Evolution: ducation and Outreach, 8(1), 9. https://doi.org/10.1186/s12052-015-0037-4

Natural History Museum. (2018). Human Evolution. Cheddar Man: Mesolithic Britain's blue-eyed boy. https://www.nhm.ac.uk/visit/galleries-and-museum-map/human-evolution.html

Nicolaisen, L. B., \& Achiam, M. (2020). The implied visitor in a planetarium exhibition. Museum Management and Curatorship, 35(2), 143-159. https://doi.org/10.1080/09647775.2019.1691637

Olander, C., \& Ingerman, ^. (2011). Towards an inter-language of talking science: Exploring students' argumentation in relation to authentic language. Journal of Biological Education, 45(3), 158-164. https://doi.org/10.1080/00219266.2011.591414

Orlander, A. A., \& Wickman, P.-O. (2011). Bodily experiences in secondary school biology. Cultural Studies of Science Education, 6(3), 569-594. https://doi.org/10.1007/s11422-010-9292-4

Orlander, A. A., Todd, S., \& Wickman, P.-O. (2015). Becoming a man and a woman in secondary school practice. Nordic Studies in Education, 3, 233-250.

Pillay, M. (2010). A critical evaluation of representations of hominin evolution in the museums of the Cradle of Humankind World Heritage Site, South Africa. [Master's thesis, University of the Witwatersrand]. Electronic Theses and Dissertations (ETD). http://wiredspace.wits.ac.za/handle/10539

Piqueras, J., Hamza, K. M., \& Edvall, S. (2008). The practical epistemologies in the museum. Journal of Museum Education, 33(2), 153-164. https://doi.org/10.1080/10598650.2008.11510596

Powers, K. E., Prather, L. A., Cook, J. A., Wooley, J., Bart, H. L., Monfils, A. K., \& Sierwald, P. (2014). Revolutionizing the use of natural history collections in education. Science Education Review, 13(2), 24-33.

Puvirajah, A., Verma, G., \& Webb, H. (2012). Examining the mediation of power in a collaborative community: Engaging in informal science as authentic practice. Cultural Studies of Science Education, 7(2), 375-408. https://doi.org/10.1007/s11422-012-9394-2

Quistgaard, N. (2010). Autentiske spørgsmål kan skabe ægte engageret dialog på naturhistoriske museer [Authentic questions can generate engaged dialogue in natural history museums]. MONA - Matematik- Og Naturfagsdidaktik, 3, 49-76. https://tidsskrift.dk/mona/article/view/36152

Record, L. A. (2018). Understanding best practices in exhibit design to improve learning of evolutionary biology in non-formal education facilities in Alberta. [Masters's thesis, University of Calgary]. The Vault: Electronic Theses and Dissertations. https://prism.ucalgary.ca/handle/1880/107740

Rennie, L. J. (2014). Learning science outside of school. In N. G. Lederman \& S. K. Abell (Eds.), Handbook of Research on Science Education (pp. 120-144). Routledge.

Rennie, L. J., Feher, E., Dierking, L. D., \& Falk, J. H. (2003). Toward an agenda for advancing research on science learning in out-of-school settings. Journal of Research in Science Teaching, 40, 112120. https://doi.org/10.1002/tea.10067

Reno, P. L., Meindl, R. S., McCollum, M. A., \& Lovejoy, C. O. (2003). Sexual dimorphism in Australopithecus afarensis was similar to that of modern humans. Proceedings of the National Academy of Sciences, 100(16), 9404-9409. https://doi.org/10.1073/pnas.1133180100

Scott, M. (2007). Rethinking evolution in the museum. Routledge.

Seals, M. A. (2010). Teaching students to think critically about science and origins. Cultural Studies of Science Education, 5(1), 251-255. https://doi.org/10.1007/s11422-009-9251-0

Silfver, E. (2019). Gender performance in an out-of-school science context. Cultural Studies of Science Education, 14(1), 139-155. https://doi.org/10.1007/s11422-017-9851-z

Smith, M. U. (2010). Current status of research in teaching and learning evolution: I. Philosophical/epistemological issues. Science \& Education, 19(6), 523-538. https://doi.org/10.1007/s11191-009-9215-5

Smith, M. U., Siegel, H., \& McInerney, J. D. (1995). Foundational issues in evolution education. Science \& Education, 4(1), 23-46. https://doi.org/10.1007/BF00486589

Smithsonian (2020). Reconstructions of early humans. Smithsonian. National Museum of Natural History. https://humanorigins.si.edu/exhibit/reconstructions-early-humans

Susman, R. L. (1994). Fossil evidence for early hominid tool use. Science, 265(5178), 1570-1573. https:// doi.org/10.1126/science.8079169

Swedish Museum of Natural History. (2020a). The Human Journey. https://www.nrm.se/besokmuseet/utsta llningar/denmanskligaresan.5713.html

Swedish Museum of Natural History. (2020b). Den mänskliga resan 2 [The Human Journey 2] [Video]. YouTube. https://www.youtube.com/watch?v=hvJTdH072Y8

Swedish Research Council (2017). Good research practice. Swedish Research Council. https://www.vr.se/ download/18.5639980c162791bbfe697882/1555334908942/Good-Research-Practice_VR_2017.pdf

Tare, M., French, J., Frazier, B. N., Diamond, J., \& Evans, E. M. (2011). Explanatory parent-child conversation predominates at an evolution exhibit. Science Education, 95(4), 720-744. https://doi.org/10.1002/ sce. 20433 
Taylor, R.S., \& Ferrari, M. (2011). Epistemology and science education: Understanding the evolution vs. intelligent design controversy. Routledge.

Thagard, P., \& Findlay, S. (2010). Getting to Darwin: Obstacles to accepting evolution by natural selection. Science \& Education, 19(6), 625-636. https://doi.org/10.1007/s11191-009-9204-8

The Swedish Agency for Education. (2018a). Curriculum for the compulsory school, preschool class and school-age educare. https://www.skolverket.se/publikationsserier/styrdokument/2018/curriculum-forthe-compulsory-school-preschool-class-and-school-age-educare-revised-2018

The Swedish Agency for Education. (2018b). Curriculum for the upper secondary school. https://www.skolv erket.se/publikationsserier/styrdokument/2013/curriculum-for-the-upper-secondary-school

Thompson, H. (2014). Paleoartist brings human evolution to life. Smithsonian Magazine. https://www.smith sonianmag.com/science-nature/bringing-human-evolution-life-180951155/

Toups, M. A., Kitchen, A., Light, J. E., \& Reed, D. L. (2010). Origin of clothing lice indicates early clothing use by anatomically modern humans in Africa. Molecular Biology and Evolution, 28(1), 29-32. https://doi.org/10.1093/molbev/msq234

Wiber, M. G. (1994). Undulating women and erect men: Visual imagery of gender and progress in illustrations of human evolution. Visual Anthropology, 7(1), 1-20. https://doi.org/10.1080/08949468.1994. 9966633

Wiber, M. G. (1997). Erect men/undulating women. The visual imagery of gender, "race” and progress in reconstructive illustrations of human evolution. Wilfrid Laurier University Press.

Wickman, P.-O. (2004). The practical epistemologies of the classroom: A study of laboratory work. Science Education, 88(3), 325-344. https://doi.org/10.1002/sce.10129

Wonders, K. (2003). Habitat Dioramas and the issue of nativeness. Landscape Research, 28(1), 89-100. https://doi.org/10.1080/01426390306532

Zihlman, A. (1997). The Paleolithic glass ceiling: Women in human evolution. In L. Hager (Ed.), Women in human evolution (pp. 91-113). Routledge.

Publisher's Note Springer Nature remains neutral with regard to jurisdictional claims in published maps and institutional affiliations. 